\title{
Molecular cloning and functional characterization of an ATP-binding cassette transporter OtrC from Streptomyces rimosus
}

\author{
Lan Yu ${ }^{1,2}$, Xiangyun Yan ${ }^{1}$, Long Wang ${ }^{1}$, Ju Chu' ${ }^{1}$ Yingping Zhuang ${ }^{1}$, Siliang Zhang ${ }^{1 *}$ and Meijin Guo ${ }^{1 *}$
}

\begin{abstract}
Background: The otrC gene of Streptomyces rimosus was previously annotated as an oxytetracycline (OTC) resistance protein. However, the amino acid sequence analysis of OtrC shows that it is a putative ATP-binding cassette $(A B C)$ transporter with multidrug resistance function. To our knowledge, none of the $A B C$ transporters in S. rimosus have yet been characterized. In this study, we aimed to characterize the multidrug exporter function of OtrC and evaluate its relevancy to OTC production.

Results: In order to investigate OtrC's function, otrC is cloned and expressed in E. coli The exporter function of OtrC was identified by ATPase activity determination and ethidium bromide efflux assays. Also, the susceptibilities of OtrC-overexpressing cells to several structurally unrelated drugs were compared with those of OtrC-non-expressing cells by minimal inhibitory concentration (MIC) assays, indicating that OtrC functions as a drug exporter with a broad range of drug specificities. The OTC production was enhanced by 1.6-fold in M4018 ( $P=0.000877)$ and 1.4fold in SR16 $(P=0.00973)$ duplication mutants, while it decreased to $80 \%$ in disruption mutants $(P=0.0182$ and 0.0124 in M4018 and SR16, respectively).
\end{abstract}

Conclusions: The results suggest that $\operatorname{OtrC}$ is an $A B C$ transporter with multidrug resistance function, and plays an important role in self-protection by drug efflux mechanisms. This is the first report of such a protein in S. rimosus, and otrC could be a valuable target for genetic manipulation to improve the production of industrial antibiotics.

Keywords: Streptomyces rimosus, OtrC, ATP-binding cassette transporter, ATP hydrolysis, Multidrug resistance

\section{Background}

Clinical multidrug resistance (MDR) to bactericidal antibiotics is driving research into the underlying mechanisms of resistance and the discovery of novel drugs. In the past decade, numerous resistance proteins have identified, including the ubiquitous ATP-binding cassette $(\mathrm{ABC})$ family of multidrug transporters [1-6]. These integral membrane proteins mediate the active extrusion of antibiotics and toxic compounds from cells. Recent crystal structure analyses revealed that some ABC-type multidrug proteins, such as MsbA from E. coli, Vibrio cholera, and Salmonella typhimurium [5-7] and BtuCD from E. coli [8], also mediate the import of substrates by altering the conformation of the transmembrane helices

\footnotetext{
*Correspondence: siliangz@ecust.edu.cn; guo_mj@ecust.edu.cn

${ }^{1}$ State Key Laboratory of Bioreactor Engineering, East China University of Science and Technology, 130 Meilong Road, Shanghai 200237, P.R. China Full list of author information is available at the end of the article
}

(TMs) from an 'outward-facing' state to an 'inwardfacing' state [9]. The ABC transporters represent $2 \%$ of gene products in bacteria and play a critical role in their adaptation to the environment [10]. Some are involved in resistance to chemotherapy and, therefore, applied research has increasingly focused on the elucidation of the transportation mechanism of these proteins [11]. Furthermore, the self-protection afforded by the antibiotic producers is dependent on its endogenous drug resistance proteins. Therefore, these resistance proteins may also represent targets for antibiotic production improvement strategies $[12,13]$.

Streptomyces rimosus, well known as an oxytetracycline (OTC) producer, has been investigated at the genetic level over many years, although only two antibiotic pump genes have been discovered to date: the OTC resistance gene, otrB [14] and a putative $\mathrm{ABC}$ transporter gene, $\operatorname{otr} C$, which has been isolated, sequenced and

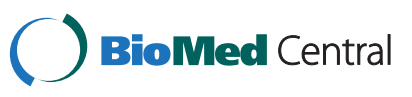


deposited in GenBank (AY509111.1). The two open read frames (orf) of the otrC gene encode a putative $A B C$ transporter ATP-binding subunit and a putative transmembrane subunit. OtrC was considered to be a putative $A B C$ transporter with an OTC resistance function based on its amino acid sequences, although no evidence in support of this has been reported to date. Generally, the location of resistance genes in the chromosome is close to the corresponding antibiotic biosynthesis clusters. In the case of OTC, the OTC cluster in S. rimosus is flanked by the resistance genes, otrA and otrB [15], while $\operatorname{otr} C$ is distant from the OTC cluster (data not published). We hypothesize that $\operatorname{tat} C$ plays a role as the MDR transporter in OTC resistance. Here, we present evidence that $\operatorname{otrC}$ encodes a protein with ATPase and multidrug efflux activities and therefore may represent a manipulation target for strategies to improve of OTC production in S. rimosus.

\section{Results}

Conserved motifs analysis and model prediction of otrC The otrC gene contains two open reading frames (ORFs), which encode a putative ATP-binding subunit (OtrC-ORF1) of $38 \mathrm{kDa}$ and a putative transmembrane subunit (OtrC-ORF2) of $30 \mathrm{kDa}$. A NCBI BLAST search of the amino acid sequence of the OtrC protein identified a number of similar proteins, the majority of which were $\mathrm{ABC}$ components of doxorubicin or MDR $\mathrm{ABC}$ transporters from various phyla.

The ATP-binding subunit usually contains conserved sequence motifs that play important roles in protein function. Therefore, an alignment of OtrC-ORF1 with DrrA [16] and Msr-ORF1 from Streptomyces [17] was performed for the identification of conserved motifs (Figure 1). The results showed that OtrC-ORF1 exhibits $41 \%$ amino acid identity with the doxorubicin resistance protein DrrA from S. peucetius and 43\% identity with the multidrug $\mathrm{ABC}$ transporter ATP -binding subunit Msr-ORF1 from S. rochei F20. The N-terminal of OtrCORF1 contains the well-described conserved Walker A and $\mathrm{B}$ motifs and the $\mathrm{ABC}$ signature sequence. These motifs are intimately involved in ATP hydrolysis [18], which indicates that OtrC belongs to the $\mathrm{ABC}$ transporter superfamily. The alignment also showed the conserved LDEADQLA and LDEVFL motifs in the C-terminal region of OtrC-ORF1. These motifs exhibit 58.6\% and $80 \%$ identity with those of DrrA and Msr-ORF1, respectively. However, the CREEM motif was absent from OtrC-ORF1 and Msr-ORF1. The LDEVFL motif is known to be involved in the doxorubicin-stimulated nucleotide-binding function and also exists in the MDR protein [18]. Therefore, it was speculated that the ATPase activity of OtrC-ORF1 is stimulated by doxorubicin and other drugs.

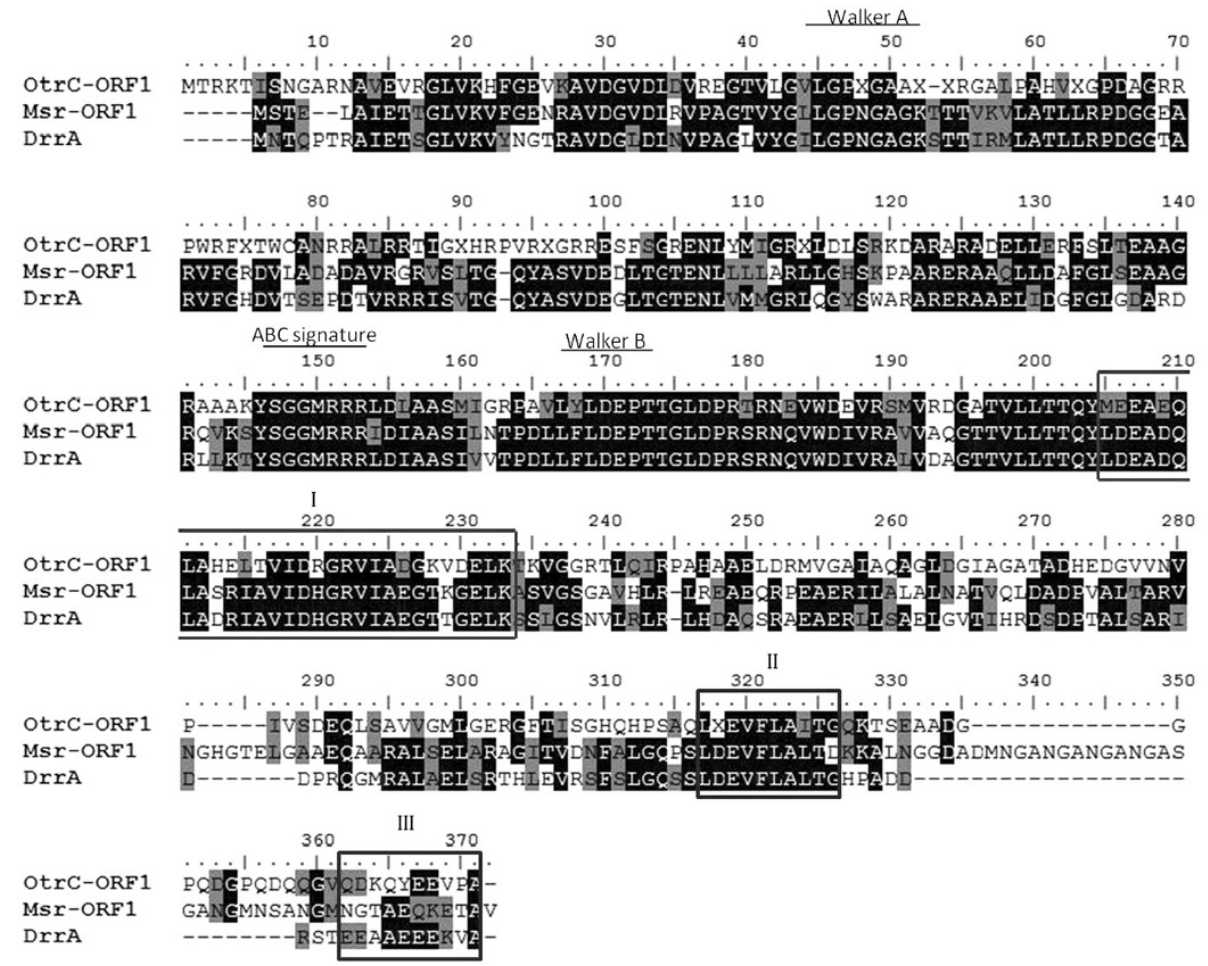

Figure 1 Alignment of the amino acid sequence of the OtrC-ORF1 region with DrrA and Msr-ORF1. The dark gray regions show residues that are highly conserved, whereas the residues in light gray are less well conserved. 
In contrast, the transmembrane subunit has more sequence diversity and varies in the total number of transmembrane helices. OtrC-ORF2 was then aligned with other $\mathrm{ABC}$ transporters (Figure 2). The conserved EAA motif $\left(\mathrm{E}_{1} \mathrm{AA}_{3} \mathrm{RALG}_{7}\right)$ that is present in MalG was believed to be present only in the importers of the $A B C$ family, while the $\mathrm{G}_{-2} \mathrm{E}_{-1} \ldots \mathrm{A}_{3} \mathrm{R} / \mathrm{K}_{4} \ldots \mathrm{G}_{7}$ motif present in BtuC, which has similarity with EAA motif, has been identified in both the import and export functions of ABC transporters [19]. The alignment analysis revealed the present of a $G_{-2} \ldots . R_{4}$ motif that was present in all $\mathrm{ABC}$ transporter proteins with an exporter function, including EpeA, DrrB, MsbA and BtuC. The $\mathrm{G}_{-2}$ residue has been identified to correspond with drug sensitivity by site-directed mutagenesis [19]. We therefore assumed that the $G_{-2} \ldots R_{4}$ motif was involved in the drug export function of the $\mathrm{ABC}$ transporter and $\mathrm{OtrC}$ functions as a drug exporter.

The prediction of the secondary structure of OtrCORF2 by the PROF method using the PredictProtein program (www.predictprotein.org) indicated the presence of a N-terminal hydrophobic domain with six putative $\alpha$-helical transmembrane segments and cytoplasmic facing $\mathrm{N}$ and $\mathrm{C}$ termini. The reported canonical $\mathrm{ABC}$ systems display a modular architecture composed of two nucleotide-binding domains/subunits and two transmembrane domains/subunits. Therefore, it can be concluded that the OtrC system is a tetrameric complex composed of two homodimeric constituents, similar to that of many other bacterial ABC transporters [17].

\section{Functional characterization of OtrC}

E. coli BL21 (DE3) cells were transformed with the indicated plasmid pETC02 (Additional file 1: Figure S1), while OtrC expression was induced by IPTG and analyzed by Coomassie blue staining of the SDSpolyacrylamide gels (SDS-PAGE) and Western blotting.
A band that corresponded to the $30-\mathrm{kDa}$ OtrC-ORF2 was detected in the cytoplasmic membrane by SDSPAGE (Figure 3); however, although the OtrC-ORF2 was fused with a $\mathrm{His}_{6}$-tag at the $\mathrm{C}$ terminal, the specific band of the gene product was absent in the Western blot analysis. This could have been due to the embedding of the $\mathrm{His}_{6}$-tag by protein folding. The specific band that corresponded to the $68 \mathrm{kDa}-O \operatorname{trC}, 38 \mathrm{kDa}-O t r C-O R F 1$ subunit could be visualized in whole cell protein fraction by SDS-PAGE and Western blot analysis (Figure 3). These specific bands of OtrC and its subunits were absent from E. coli that carried the empty pET28a plasmid, which suggested the successful heterologous expression of OtrC in E. coli.

The malachite green assay was employed to determine the ATPase activity of OtrC. The results showed that the ATPase activity of E. coli/pETC02 (121.3 nM. $\left.\mathrm{ml}^{-1} \cdot \mathrm{min}^{-1}\right)$ was significantly higher than that of $E$. coli/pET28a $\left(8.1 \mathrm{nM} \cdot \mathrm{ml}^{-1} \cdot \mathrm{min}^{-1}\right.$ ) (Additional file 1: Figure S2 and Figure 4), which indicates as expected that OtrC has ATP hydrolysis activity.

Fluorimetric EB, a cationic substrate of ABC transporters, was employed for the efflux assays to test if OtrC can mediate the transport coupled to ATP hydrolysis. The cells of $E$. coli transformants were suspended in $20 \mu \mathrm{M}$ EB solution, and the EB efflux activity was triggered by glucose. As shown in Figure 5A, the energization of cells resulted in an increased rate of EB extrusion for OtrC-expressing cells compared to the control cells, which indicates that OtrC displays an ATP-dependent extrusion activity. The efflux activity of OtrC was further confirmed by determining the effect of an ABC transporter inhibitor orthovanadate on the accumulation of EB in OtrC-expressing and OtrC-nonexpressing cells. As the glycolysis pathway also can be inhibited by orthovanadate, cells were energized with ATP instead of glucose. As shown in Figure $5 \mathrm{~B}$, orthovanadate increased the

$$
\begin{aligned}
& \text { S. rimosus OtrC-ORF2 } 7 \text { A A P G K P G R P G A D E G R I G L R A H L R } \\
& \text { S.clavuligernsEpeA } 318 \text { G A V L S G L L A G H L A R R A S V R A A V T } \\
& \text { S.pencetiuls DriB 16G Q L R T V L S A G E R P A R A T A V S A T L } \\
& \text { E.coli MsbA } 112 \text { P V S F F D K Q S G T L L S R I T Y D S E Q V } \\
& \text { E.coli Btuc 208S R P M N M L A L G E I S A R Q L G L P L W F } \\
& \text { E.coli MalG } 177 \mathrm{~F} \mathrm{~A} \mathrm{~F} \mathrm{M} \mathrm{A} \mathrm{V} \mathrm{P} \mathrm{K} \mathrm{G} \mathrm{H} \mathrm{I} \mathrm{E} \mathrm{A} \mathrm{A} \mathrm{T} \mathrm{A} \mathrm{F} \mathrm{G} \mathrm{F} \mathrm{T} \mathrm{H} \mathrm{G} \mathrm{Q}
\end{aligned}
$$

Figure 2 Alignment of the amino acid sequence of predicted conserved motifs of the transmembrane subunit, OtrC-ORF2, MsbA, DrrB, BtuC and MalG. The dark gray regions show residues that are highly conserved, whereas the residues in light gray are less well conserved. The first amino acid in the sequence of each protein is shown. 


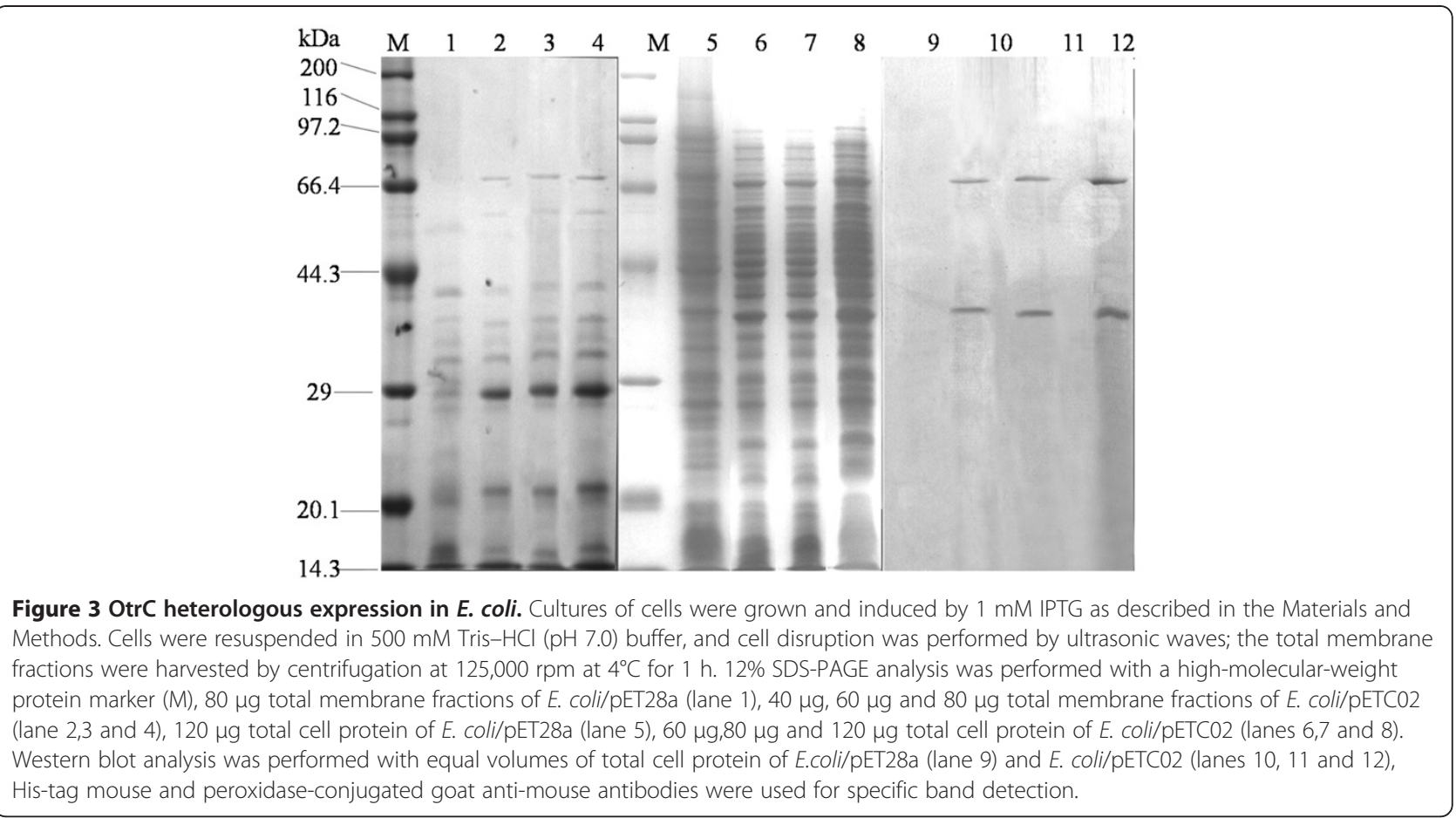

level of EB uptake in OtrC-expressing cells, while no increase was observed in OtrC-nonexpressing cells. These observations indicate that orthovanadate inhibited the OtrC-mediated efflux of EB.

\section{Effect of OtrC expression on drug susceptibility}

In order to identify the MDR function of OtrC, the OtrC-overexpressing and non-expressing mutants of the $S$. rimosus M4018 strain were constructed and identified as described in the Materials and Methods (Additional file 1: Figures S3 and S4).

Several drugs with clinical importance were employed for drug susceptibility assays of OtrC-overexpressing and OtrC-nonexpressing strains of $E$. coli as well as $S$. rimosus. As shown in Tables 1 and 2, the MIC for ampicillin increased by 1.3 -fold, and in the order of 3.3 fold for doxorubicin, 2-fold for EB and vancomycin in E. coli/pETC02 compared with E. coli/pET28a. The MICs of E. coli/pETC02 to OTC and ofloxacin were enhanced at $5 \mu \mathrm{g} / \mathrm{ml}$ and $2 \mu \mathrm{g} / \mathrm{ml}$, respectively; in contrast, the growth of $E$. coli/pET28a was completely inhibited by these drugs. However, the overexpression of OtrC had no effect on the susceptibility of $E$. coli to rifampicin, erythromycin and streptomycin (Table 1).

A clear difference in drug sensitivity to these drugs was also found in S. rimosus mutants M4018/pSEC and M4018/pKC $\Delta$ otrC with respect to the control strain M4018/pSET152. The overexpression of OtrC in M4018/ pSEC resulted in significantly elevated MICs to ampicillin (3-fold), OTC (1.7-fold), doxorubicin (2-fold), EB (2-fold) and ofloxacin (20-fold). Furthermore, the OtrC overexpressing mutant survived with $500 \mu \mathrm{g} / \mathrm{ml}$ vancomycin, while the growth of M4018/pSET152 was completely inhibited by vancomycin (Table 2). The MICs for ampicillin and doxorubicin in the OtrC-disrupting mutant M4018/pKC $\Delta$ otrC were decreased by $20 \%$, compared to a

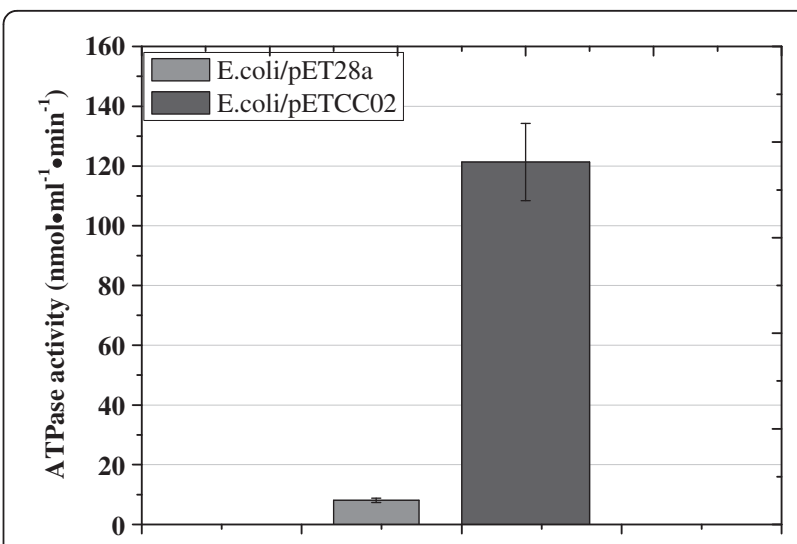

Figure 4 ATPase assay of OtrC-overexpressing and OtrCnonexpressing cells. OtrC from S. rimosus was introduced into the E.coli BL21(DE3) strain using a pETC02 plasmid, and the E.coli BL21 (DE3) carrying the empty pET28a was used as the control. The cells were induced by $1 \mathrm{mM} \mathrm{IPTG}$ at $30^{\circ} \mathrm{C}$ for $10 \mathrm{~h}$, and then collected by centrifugation. The cell wall was digested by lysozymes and the membrane vesicles were harvested by centrifugation. The ATPase activity of E.coli/pETC02 (dark gray) was determined compared with to the E. coli/pET28a control (light gray). Vertical error bars corresponded to the standard error of the mean of three replicated samples. 

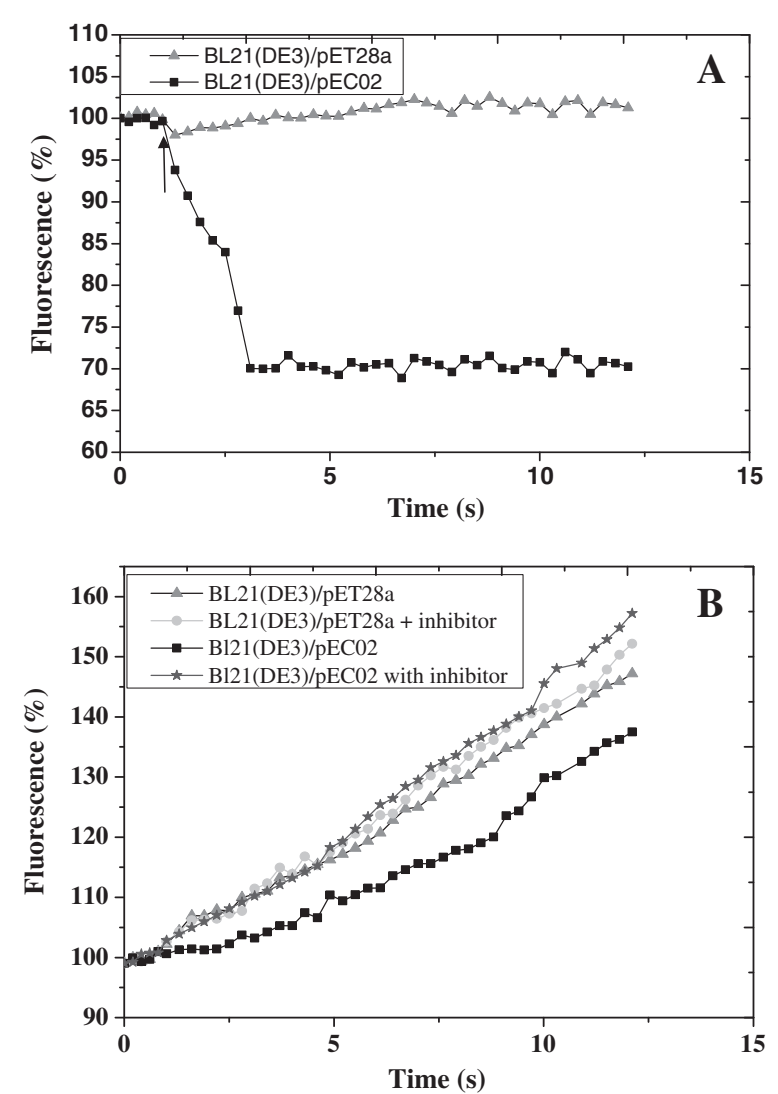

Figure 5 Ethidium bromide (EB) transport in OtrCoverexpressing cells and nonexpressing cells. A: The OtrCexpressing cells (black squares) and the control cells (gray triangles) were cultured and induced with $1 \mathrm{mM} \mathrm{IPTG}$, and then resuspended in $\mathrm{KPi}$ buffer ( $\mathrm{pH}$ 7.0) containing $5 \mathrm{mM} \mathrm{MgSO}_{4}$. The de-energized cells $\left(\mathrm{OD}_{600}=0.5\right)$ were pre-equilibrated with $20 \mu \mathrm{M} \mathrm{EB}$ at $30^{\circ} \mathrm{C}$, and $25 \mathrm{mM}$ glucose was added (at the arrow) to initiate EB efflux. B: The effect of orthovanadate on the accumulation of EB in OtrC-expressing and nonexpressing cells. E.coli/pETC02 cells were cultured, induced and collected; the washed cells $\left(\mathrm{OD}_{600}=0.5\right)$ were incubated for $10 \mathrm{~min}$ at $30^{\circ} \mathrm{C}$ in the presence (dark gray stars) or absence (black squares) of $0.5 \mathrm{mM}$ orthovanadate, followed by the addition of $20 \mu \mathrm{M}$ ethidium bromide (EB) along with $2 \mathrm{mM} \mathrm{Mg-ATP}$ (arrow). The E. coli/pET28a cells were used as the control, treated with (grey triangles) or without (light gray circles)orthovanadate as described above. The development of fluorescence of the DNA-ethidium complex in the cell suspension was monitored at $30^{\circ} \mathrm{C}$ every $20 \mathrm{~s}$. The fluorescence intensity before the addition of glucose or ATP was normalized to $100 \%$.

decrease of $67 \%$ for OTC; however, the disruption of OtrC had no effect on EB and vancomycin sensitivity (Table 2). Neither the OtrC-overexpressing mutant nor the OtrCdisrupting mutant showed any alternation in the sensitivity to rifampicin, erythromycin and streptomycin (Table 1), which was in agreement with the results of drug susceptibility assays in OtrC-overexpressing E. coli cells.

The $\operatorname{otr} C$ overexpressing cells showed a significantly enhanced MIC to ampicillin, OTC, doxorubicin, EB, ofloxacin and vancomycin, which indicated that OtrC
Table 1 Susceptibilities of $E$. coli mutants to several drugs

\begin{tabular}{lll}
\hline Antibiotics $(\boldsymbol{\mu g} / \mathbf{m l})$ & BL21(DE3)/pET28a & BL21(DE3)/pETC02 \\
\hline Ampicillin & 40 & 50 \\
Rifampicin & 40 & 40 \\
Oxytetracycline & - & 5 \\
Doxorubicin & 150 & 500 \\
Ethidium bromide & 200 & 400 \\
Vancomycin & 2 & 4 \\
Ofloxacin & - & 2 \\
Erythromycin & 10 & 10 \\
Streptomycin & 15 & 15 \\
\hline
\end{tabular}

$'-$, cell growth was completely inhibited.

functions as a drug exporter with a broad range of drug specificities.

\section{OtrC expression affects OTC production in S. rimosus}

In order to explore the applications of OtrC for antibiotic production, the identified recombinant plasmids, pSEC and $\mathrm{pKC} \Delta \mathrm{otrC}$ (Additional file 1: Figures S2 and S3), were introduced into an industrial OTC overproducer, SR16, after identification as described in the Materials and Methods. Mutant strains were used for OTC production measurements in addition to the mutant derived from strain type M4018. The results showed that the mutant M4018/pSEC yielded an OTC production peak of $327.0 \mu \mathrm{g} / \mathrm{ml}$ at $96 \mathrm{~h}$, which was markedly higher than that of M4018/pSET152 $(202.8 \mu \mathrm{g} / \mathrm{ml}$ at $120 \mathrm{~h})$, while the $\operatorname{otrC}$ disruption mutant M4018/pKC $\Delta$ otrC yielded a decreased OTC production peak of $170.0 \mu \mathrm{g} / \mathrm{ml}$ at $168 \mathrm{~h}$ (Figure 6A). The OTC production peak in M4018/pSEC at an earlier time than the controls suggested that the OTC efflux function of OtrC plays an important role in self-protective mechanisms and OTC production.

The OTC production profile in SR16 mutants showed that the OTC production of the OtrC knock-in mutant

Table 2 Susceptibilities of S. rimosus mutants to several drugs

\begin{tabular}{llll}
\hline Antibiotics $(\boldsymbol{\mu g} / \mathbf{m l})$ & M4018/pSET152 & M4018/pSEC & M4018/pKC $\mathbf{c o t r} \mathbf{C}$ \\
\hline Ampicillin & 500 & 1500 & 100 \\
Rifampicin & 200 & 200 & 200 \\
Oxytetracycline & 1500 & 2500 & 1000 \\
Doxorubicin & 500 & 1000 & 100 \\
Ethidium bromide & 4 & 8 & 4 \\
Vancomycin & 1 & 500 & - \\
Ofloxacin & 20 & 400 & 4 \\
Erythromycin & 2 & 2 & 2 \\
Streptomycin & + & + & + \\
\hline
\end{tabular}

'+', cell growth could not be inhibited by the antibiotic; '-', cell growth was completely inhibited. 

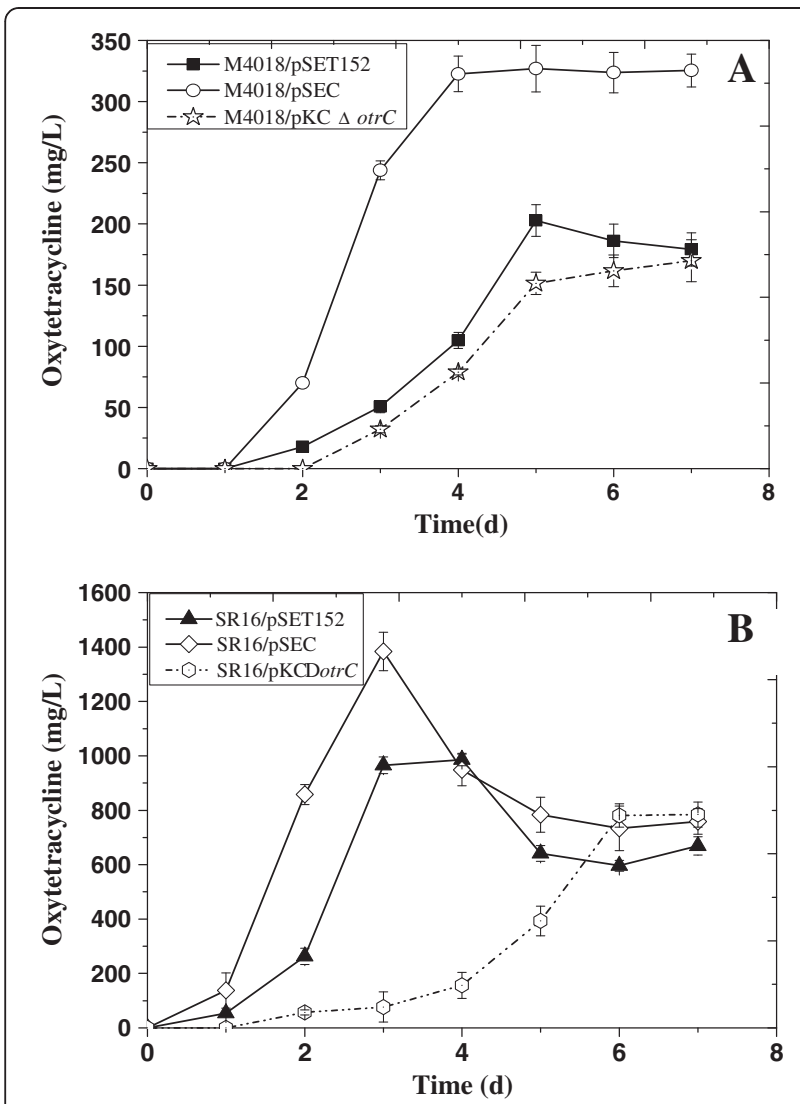

Figure 6 Specific OTC production of S. rimosus strains. A: An extra copy of otrC was introduced into the S. rimosus M4018 chromosome using the recombinant integrative vector PSEC (white circles). The otrC disruption mutant of M4018 was constructed using the temperature-sensitive recombinant plasmid pKC $\Delta$ otrC (white stars). M4018/pSET152 (black squares) served as the control. B: An extra copy of otrC was introduced into the chromosome of $S$. rimosus SR16 using the integrative vector PSEC (white diamonds). The otrC disruption mutant of SR16 was constructed using the temperature-sensitive plasmid pKC $\Delta$ otrC (white hexagons). SR16 that carried the empty pSET152 plasmid was used as the control (black triangles). S. rimosus strains were grown in MS plates, spores were inoculated into GYCS medium to the final concentration of $1 \times 10^{6}$ spores per $\mathrm{ml}$, after which they were cultured at $28^{\circ} \mathrm{C}$ on a rotary shaker (260 rpm) for $72 \mathrm{~h}$; $1 \%$ seed culture was transferred into SC medium cultured at $30^{\circ} \mathrm{C}$ on a rotary shaker (260 rpm) for $7 \mathrm{~d}$. OTC was measured by HPLC. Vertical error bars correspond to the standard error of the mean of three replicated cultures.

SR16/pSEC reached a peak of $1,384.1 \mathrm{mg} / \mathrm{L}$ at $72 \mathrm{~h}$, which was 1.4-fold greater than that of SR16/pSET152 at $96 \mathrm{~h}$. In contrast, the production of OTC was markedly reduced in the disrupted mutant SR16/pKC $\Delta$ otrC. It yielded an OTC production rate of $784.2 \mathrm{mg} / \mathrm{L}$ at $168 \mathrm{~h}$, which was approximately $80 \%$ of the peak production of SR16/pSET152 (Figure 6B). These results were in agreement with the above-mentioned conclusion that OtrC expression efficiently affects OTC production in S. rimosus.

The transcription levels of otrC in otrC-expressing $S$. rimosus strains were measured by $\mathrm{qRT}-\mathrm{PCR}$. The transcription level of $\operatorname{otr} C$ was significantly enhanced in S. rimosus M4018/pSEC compared with the control strain M4018/pSET152 (Figure 7A), which explains the significant improvement of OTC production in M4018/ pSEC. For the industrial overproducer SR16, the otrC duplication mutant SR16/pSEC showed a marked enhancement in the transcription of otrC compared with the negative control, SR16/pSET152 (Figure 7B). These results suggest that $\operatorname{otr} C$ overexpression was responsible for OTC overproduction in M4018/pSEC and SR16/ pSEC.

\section{Discussion}

The bacterial ATP-binding cassette (ABC) family of multidrug transporters contains very important resistance

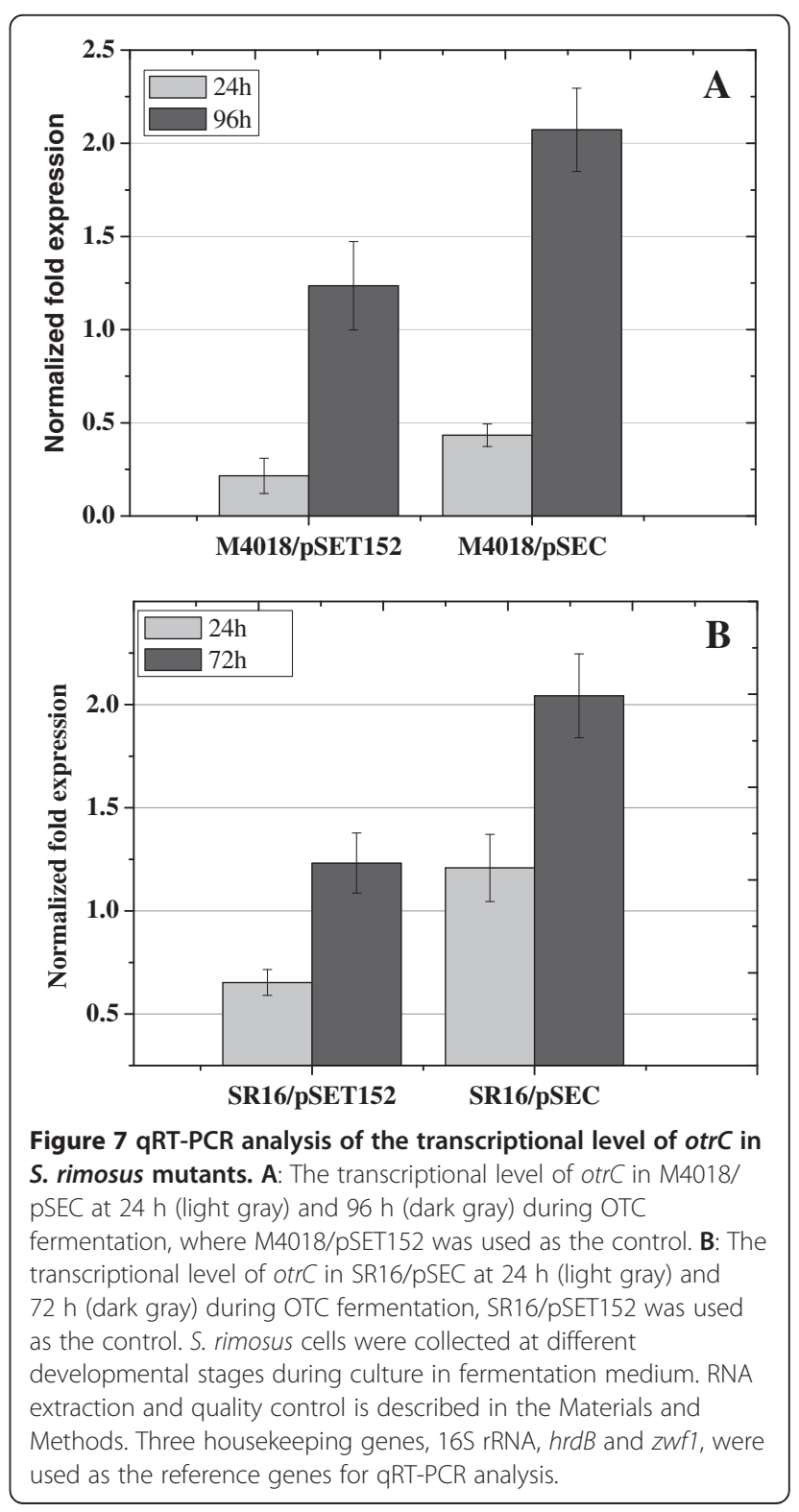


proteins that have evolved over a long period. In the present study, we characterized the function of OtrC, a putative $\mathrm{ABC}$ transporter, from $S$. rimosus and report that OtrC has major effects on the overproduction of OTC in S. rimosus.

\section{The multidrug exporter function of OtrC from S. rimosus}

The results of the amino acid sequence alignment analysis showed that OtrC contains a N-terminal ATPase activity-related conserved motif and a drug resistance activity-related motif at the C-terminal (Figure 1). As the highly conserved LDEVFL motif of DrrA at the Cterminal was shown to be involved in doxorubicin efflux, this indicated that OtrC might also be associated with antibiotic resistance. The present results (Figure 8) show that drug susceptibility levels to tetracycline, EB and floxacin were enhanced in strains of E. coli and S. rimosus that overexpressed OtrC compared to corresponding OtrC-nonexpressing strains, which were very similar findings to those published previously regarding DrrA and Msr-ORF1 [4,17]. Additionally, we hypothesized that the low level of conservation of the amino acid sequence in the LDEADQLA motif of OtrC-ORF1 (Figure 1) may be responsible for the consistently low sensitivity to erythromycin of OtrC-expressing cells.

OtrC-ORF2 contains the $G_{-2} \ldots R_{4}$ conserved motif, but does not possess the EAA conserved motif (Figure 2). The former might be involved in drug export function, and the latter was identified to be involved in import function [19]. To verify the function of OtrC as a drug transporter in cells, the $E$. coli cells that overexpressed OtrC were given glucose, which resulted in the extrusion of EB rather than its uptake as was expected (Figure 5). Furthermore, when the ABC transporter inhibitor orthovanadate was added, EB extrusion was not observed in the OtrC-expressing cells supplemented with ATP. This indicated that OtrC is responsible for the EB export activity in OtrC-expressing E. coli transformant. Hence, the drug resistance mechanism of OtrC could be based on ATP hydrolysis coupled with its transport ability.

The OtrC-expressing E. coli transformant showed significantly enhanced susceptibilities to ampicillin, doxorubicin, OTC, EB, vancomycin and ofloxacin (Figure 8A). However, the MICs of $S$. rimosus mutants to ampicillin, OTC, doxorubicin and ofloxacin were markedly amplified compared with controls (Figure $8 \mathrm{~B}$ ), which suggested that OtrC could play an important role in the self-protection mechanisms of $S$. rimosus. Interestingly, the MIC of M4018/pSEC to vancomycin was $500 \mu \mathrm{g} / \mathrm{ml}$, and the growth of M4018/pKC $\Delta$ otrC and M4018/pSET152 was completely inhibited under these conditions. This implies that OtrC acts as an efficient vancomycin efflux pump. Additionally, the significantly enhanced vancomycin resistance activity in S. rimosus M4018/pSEC might be
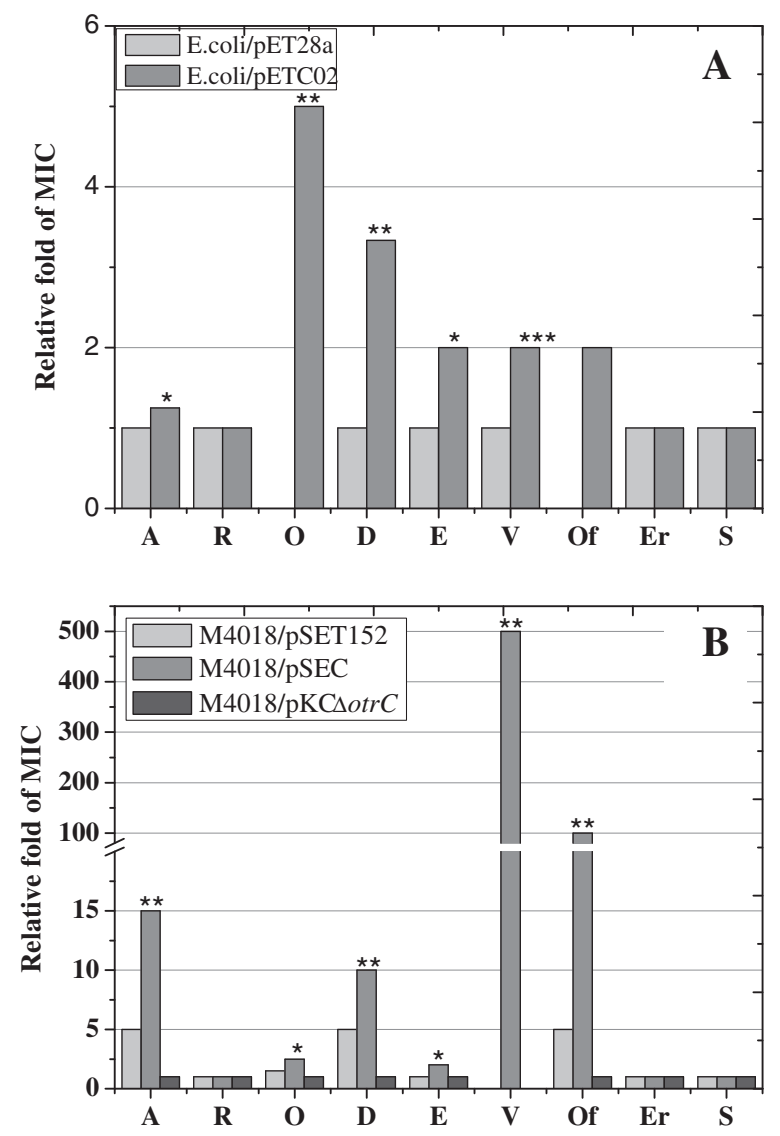

Figure 8 The relative fold change of MICs of OtrC-expressing cells with different drugs compared to OtrC-nonexpressing cells. A: The relative change in the MIC of OtrC-expressing E. coli/ pETCO2 cells (gray) to ampicillin (A), rifampicin (R), oxytetracycline $(\mathrm{O})$, doxorubicin $(\mathrm{D})$, ethidium bromide $(\mathrm{E})$, vancomycin $(\mathrm{V})$, ofloxacin (Of), erythromycin (Er) and streptomycin (S), using the OtrCnonexpressing E.coli/pET28a cells (light gray) as the controls. The relative change in MIC to the drug that could completely inhibit the cell growth of E.coli/pET28a was set as "0", while the MIC of drug which could not inhibit the cell growth was set as "1". Cells were grown in LB liquid medium supplemented with kanamycin, IPTG and different concentrations of test drugs at $37^{\circ} \mathrm{C}$, and spun at $170 \mathrm{rpm}$ for $12 \mathrm{~h}$. Cells were then resuspended in fresh $L B$ and spread immediately on the LB plates with kanamycin, IPTG and different concentration of the test drugs. The MICs to drugs were determined after the plates were cultured at $37^{\circ} \mathrm{C}$ for $12 \mathrm{~h}$. B: The relative fold of MICS of OtrC-expressing S. rimosus mutants, M4018/ pSET152 (light gray) and M4018/pSEC (gray), to the above-

mentioned drugs, using the OtrC-nonexpressing mutant M4018/ pKC $\Delta$ otrC (dark gray) as the control. The relative change in the MIC to drugs that could completely inhibit the cell growth of M4018/ pKC $\Delta$ otrC was set as " 0 ", while the MIC of drug which could not inhibit the cell growth was set as "1". Cells were grown in TSB liquid medium supplemented with different concentrations of drugs at $28^{\circ} \mathrm{C}$, and the centrifuged at $220 \mathrm{rpm}$ for $30 \mathrm{~h}$, resuspended in fresh TSB and spread immediately on TSB plates with different concentrations of test drugs. The MICs of drugs were determined after the plates were cultured at $28^{\circ} \mathrm{C}$ for $3 \mathrm{~d} .{ }^{* *}$ indicate significantly higher MIC values than the control cells; * indicate higher MIC values than the control cells. 
attributed to the strong constitutive ermE $E^{*}$ promoter, which results in the overexpression of OtrC during the early growth phase.

Effect of OtrC expression on OTC production in S. rimosus The M4018 strain showed a stable production of OTC. In contrast, the SR16 mutants showed an obvious drop of OTC production after 3 days, which was probably due to the instability of SR16 (Figure 7). A red pigment was observed during SR16 fermentation (date not published), which, to our knowledge, has not been previously described in S. rimosus. We speculate that another competitive secondary metabolic pathway was activated in SR16 during the traditional mutation.

The real-time qRT-PCR analysis showed that OtrC overexpression could lead to a significant OTC production improvement by secreting OTC out of cells in both the M4018S. rimosus strain and an industrial overproducer, SR16. Hence, it is reasonable to suggest that otrC could be a valuable target for genetic manipulation, such as introducing extra copies of the $\mathrm{ABC}$ transporter $[12,13]$, overexpressing the pathway genes with the use of transcription regulators [20-22] and the replacement of heterologous promoters [23,24], in order to yield the overproduction of OTC.

\section{Conclusion}

OtrC is a putative ABC-type transporter in S. rimosus, although it has been considered to be an OTC resistance protein. However, the drug resistance function and mechanism of OtrC have not been studied previously. In this study, the alignment of the amino acid sequence of OtrC suggested that it could belong to an ABC superfamily and could act as an ATP-binding drug exporter, which was further identified by ATPase activity determination and EB efflux assays in this study. The results of the drug susceptibility tests showed that OtrC confers a functional resistance toward a broad range of structurally unrelated drugs. Hence, OtrC is a multidrug resistance protein based on an ATP hydrolysis-dependent active efflux mechanism. It is the first reported multidrug resistance ABC transporter in S. rimosus.

The further investigation of mutations of conserved amino acid residues that inhibit the OtrC pump could be valuable for controlling drug resistance in clinically important pathogens. Improvements in OTC production were successfully made by introducing an extra copy of otrC into the high-performance SR16 strain, while the disruption mutant displayed a decreased OTC yield. This highlights the potential value of OtrC in OTC industrial production. Future studies on the OTC efflux activity of OtrC and the effects of OtrC overexpression in S. rimosus will contribute to improvements in OTC production.

\section{Methods}

\section{Bacterial strains, plasmids, antibiotics and antibodies}

The bacterial strains used in this study were E. coli DH5 $\alpha$, ET12567 (pUZ8002) [25], BL21 (DE3), S. rimosus M4018 (a typical strain, gift from Prof. Iain S Hunter, University of Strathclyde, UK), and SR16 (an industrial overproducer obtained by traditional strain improvement, Shanxi Tongxing Antibiotic Company, China).

The plasmids used in this study included pMD19-T, pSET152, pKC1139, pET28a and pSEC (otrC in pSET152), pKC $\Delta$ otrC (for otrC disruption, reconstructed by pKC1139), pETC02 (otrC in pET28a). E. coli strains were screened using a LB plate with $100 \mu \mathrm{g} \cdot \mathrm{ml}^{-1}$ ampicillin, $50 \mu \mathrm{g} \cdot \mathrm{ml}^{-1}$ apramycin, $25 \mu \mathrm{g} \cdot \mathrm{ml}^{-1}$ kanamycin or $34 \mu \mathrm{g} \cdot \mathrm{ml}^{-1}$ chloramphenicol when appropriate. S. rimosus mutants were screened by TSB plates with $500 \mu \mathrm{g} \cdot \mathrm{ml}^{-1}$ apramycin or $500 \mu \mathrm{g} \cdot \mathrm{ml}^{-1} \mathrm{kanamycin}$.

Different concentration of ampicillin, oxytetracycline, doxorubicin, ethidium bromide, vancomycin, ofloxacin, rifampicin, erythromycin and streptomycin were used for the MDR assay with OtrC. His-tag mouse and peroxidase-conjugated goat anti-mouse IgG (SAB, USA) antibodies were employed for Western blotting analyses.

\section{Media and growth conditions}

Escherichia coli strains were cultured in Luria-Bertani (LB) medium (1.0\% tryptone, $1.0 \% \mathrm{NaCl}, 0.5 \%$ yeast extract) with appropriate antibiotics when necessary. $S$. rimosus strains were grown in tryptone soya broth (TSB) medium (3\% tryptone soya broth, Oxoid) for genomic DNA extraction and mycelium growth, adding appropriate antibiotics, where needed. The mannitol soya flour (MS) medium (2\% mannitol, $2 \%$ soya flour and $2 \%$ agar) was used to grow spores [26]. The seed cultures were obtained by inoculating spores into glucose yeast casein hydrolysate and sucrose (GYCS) medium (1\% glucose, $0.05 \%$ yeast extract, $1.5 \%$ casein hydrolysate, $0.28 \%$ sucrose, $\left.0.01 \% \mathrm{CaCO}_{3}\right)$. Soluble starch and corn steep liquor (SC) medium [27] (2\% soluble starch, 1\% corn steep liquor, $0.6\left(\mathrm{NH}_{4}\right)_{2} \mathrm{SO}_{4}, 0.8 \% \mathrm{CaCO}_{3}, 0.5 \% \mathrm{NaCl}$, $0.2 \%$ soy bean oil, $\mathrm{pH} 6.8$ to 7.2 ).

\section{OtrC expression in E. coli}

For OtrC heterologous expression in E. coli, the genomic DNA of M4018 was used as the template. The following primers, orf1F (5'CGCCATATGATGAC GCGAAAGACGATATCCA3') and orf1R (5’CGCGG ATCCTCATGCCGGAACCTCCTCG3'), were used to amplify the $\operatorname{otr} C$ open read frame 1 (orf1), which was introduced into the NdeI and BamHI sites (underlined); primers orf2F (5'CGCGGATCCGAAGGAGA TATACCATGAGTGCCGCGACGGT3') and orf2R (5’A TTTGCGGCCGCGGTCTTCTTGCGGAACTTGGC 3') were used to amplify otrCorf 2 which was introduced 
into the BamHI and NotI sites (underlined), and the optimized RBS sites of the T7 promoter (bold) was introduced towards the 5' end. The amplified fragments (orf1, 1,074 bp and orf2, $870 \mathrm{bp}$ ) were subcloned into T-vector for sequencing, and then digested by restriction enzymes and cloned into the pET28a vector under the T7 promoter to construct the recombinant plasmid, pET28a-otrCorf1otrCorf2 (pETC02).

After pETC02 was introduced into the E. coli BL21 (DE3) strain, for OtrC expression, the E. coli transformant (E.coli/pETC02) was cultured in LB medium with $50 \mu \mathrm{g} /$ $\mathrm{ml}$ kanamycin. The growth of the cultures was monitored by recording the optical density at $600 \mathrm{~nm}\left(\mathrm{OD}_{600}\right)$; when it reached at 0.6 , cells were induced by isopropyl beta-Dthiogalactopyranoside (IPTG) at a final concentration of $1 \mathrm{mM}$ at $30^{\circ} \mathrm{C}$, at $170 \mathrm{rpm}$ for $10 \mathrm{~h}$. The E. coli/pET28 transformant was cultured and induced under the same conditions and used as a negative control.

One-milliliter cell suspensions were centrifuged at $12,000 \mathrm{rpm}$ for $10 \mathrm{~min}$ at $4^{\circ} \mathrm{C}$, and washed with deionized water, then resuspended in $100 \mu \mathrm{l}$ Tris- $\mathrm{HCl}(500 \mathrm{mM}$ $\mathrm{pH}$ 7.0) buffer, and the cell disruption was performed by ultrasonic waves. The cell disruption suspension was centrifuged at $12,000 \mathrm{rpm}$ for $15 \mathrm{~min}$ at $4^{\circ} \mathrm{C}$ to remove the cell debris, and the total membrane fractions were then harvested by centrifugation at $125,000 \mathrm{rpm}$, at $4^{\circ} \mathrm{C}$ for $1 \mathrm{~h}$. The total protein sample and the membrane fractions were then analyzed by $12 \%$ SDS-polyacrylamide gel electrophoresis (SDS-PAGE) and Western blotting following standard procedures [26].

\section{ATPase assay of OtrC}

For the ATPase assay, E. coli transformants were cultured in LB with $50 \mu \mathrm{g} / \mathrm{ml}$ kanamycin and induced with IPTG, as described above. A cell suspension sample of $1.5 \mathrm{ml}$ with $\mathrm{OD}_{600}=0.6$ was obtained, and cells were collected by centrifugation at 10,000 rpm for $1 \mathrm{~min}$. Cells were then washed with deionized water twice. Cell walls were digested by incubation for $1 \mathrm{~h}$ at $30^{\circ} \mathrm{C}$ with $10 \mathrm{mg} / \mathrm{ml}$ lysozyme (BBI, UK), after which DNase $(100 \mu \mathrm{g} / \mathrm{ml}$, TaKaRa, Japan) and $10 \mathrm{mM} \mathrm{MgSO}_{4}$ were then added. After a 10-min incubation, the suspension was centrifuged at $16,000 \mathrm{rpm}$ for $15 \mathrm{~min}$ at $4^{\circ} \mathrm{C}$ to remove the cellular debris, and the membrane vesicles were then harvested by centrifugation at $125,000 \mathrm{rpm}$ at $4^{\circ} \mathrm{C}$ for $1 \mathrm{~h}$, and resuspended in $1.5 \mathrm{ml}$ buffer A $(50 \mathrm{mM}$ Hepes $\mathrm{pH}$ 8.0, $250 \mathrm{mM} \mathrm{NaCl}, 10 \%$ glycerol [v/v]), and used as the protein sample in immediate assays for ATPase activity [1].

The malachite green assay was used to determine the specific ATPase activity of OtrC by measuring the release of inorganic phosphate. Briefly, $2 \mathrm{mM}$ ATP was added into a $200 \mu \mathrm{l}$ protein sample, $25-\mu \mathrm{l}$ aliquots were transferred into $175 \mu \mathrm{l}$ of $10 \mathrm{mM}$ sulfuric acid to stop the reaction for $20 \mathrm{~min}$. Subsequently, $50 \mu \mathrm{l}$ of fresh malachite green/molybdate solution was added, and the absorbance at $650 \mathrm{~nm}$ was measured after incubation for 10-15 $\min [1,28]$.

The malachite green/molybdate solution was freshly prepared and it contained malachite green solutions 1 $(0.122 \%[\mathrm{w} / \mathrm{v}]$ malachite green, $20 \%[\mathrm{v} / \mathrm{v}]$ sulfuric acid), solutions $2(7.5 \%[\mathrm{w} / \mathrm{v}]$ ammonium molybdate) and solutions $3(11 \%[\mathrm{v} / \mathrm{v}]$ Tween 20$)$ at a ratio of 50:12.5:1 [1].

\section{Efflux assay of OtrC}

The E. coli/pETC02 was cultured in LB with $50 \mu \mathrm{g} / \mathrm{ml}$ kanamycin and induced with IPTG. Subsequently, the cells were collected by centrifugation at 10,000 rpm at $4^{\circ} \mathrm{C}$ for $10 \mathrm{~min}$, before being washed with 1 volume $50 \mathrm{mM} \mathrm{KPi}\left(\mathrm{pH} \mathrm{7.0)}\right.$ containing $5 \mathrm{mM} \mathrm{MgSO}_{4}$. The washed cell suspensions $\left(\mathrm{OD}_{600}=0.5\right)$ were incubated for $10 \mathrm{~min}$ at $30^{\circ} \mathrm{C}$ in the presence of $20 \mu \mathrm{M}$ ethidium bromide (EB). The EB efflux was initiated by the addition of $25 \mathrm{mM}$ glucose, and the cell suspension was used to monitor the fluorescence of DNA-EB complex by a fluorimeter (Cary Eclipse, Australia) at $30^{\circ} \mathrm{C}$ using excitation and emission wavelengths of 500 and $580 \mathrm{~nm}$, respectively, and slit widths of 5 and $10 \mathrm{~nm}$, respectively [29].

To study the effect of $A B C$ inhibitor Ortho-vanadate on the accumulation of EB in OtrC expressing and non-expressing E. coli cells [29], cells were cultured, induced, collected and washed as described above. Washed cells $\left(\mathrm{OD}_{600}=0.5\right)$ were incubated for $10 \mathrm{~min}$ at $30^{\circ} \mathrm{C}$ in the presence or absence of $0.5 \mathrm{mM}$ orthovanadate, followed by the addition of $20 \mu \mathrm{M}$ ethidium bromide (EB) along with $2 \mathrm{mM} \mathrm{Mg-ATP}$, and the fluorescence of $\mathrm{EB}$ was measured at $30^{\circ} \mathrm{C}$ as described above.

\section{OtrC knock-in and disruption in S. rimosus}

The $e r m E^{*} p$ promoter region was amplified by using E* pf (5'CCGGAATTGTACCAGCCCGACCCGAG3') and E*mpr (5) CGCGGATCCGTGGAGTGGTTCTGTATCC TACCAA 3') as the primers to amplify a 306 bp fragment encompassing the EcoRI and BamHI cloning sites. The entire $\operatorname{otr} C$ gene $(1,895 \mathrm{bp})$ encompassing the BamHI and $\mathrm{XbaI}$ sites were amplified using genomic DNA of M4018 as templates and otrCf (5' CGCGGATCCCCTCTTACGAG NAAGTCATGAAGTTCCGCCGAATGNA 3,) and otrCr (5' TGCTCTAGATCAGGTCTTCTTGCGG AACTT3') primers, where the natural RBS sequence of $\operatorname{tr} C$ was introduced into primer otrCf (bold). The fragments were cloned into a pMD19-T vector for sequencing, and the fragments were digested by the restriction enzymes after identification and inserted into a pSET152 vector to obtain the recombinant plasmid, pSET152-ermE* p-otrC (pSEC). This was identified by enzyme digesting and sequencing. Plasmid pSEC 
was introduced into E. coli ET12567 (pUZ8002) for demethylation and then introduced into the chromosomes of M4018 and SR16 by electroporation following standard procedures to generate the M4018/pSEC and SR16/pSEC mutant strains. The empty plasmid, pSET152, was introduced into M4018 and SR16 to construct M4018/pSET152 and SR16/pSET152, respectively, which were used as controls.

For the disruption of $\operatorname{otr} C$, the CZ1 and CZ2 fragments were amplified by PCR using two sets of primer pairs: CZ $_{1} \mathrm{f}$ (5'CCGGAATTCTGCCTGCCCGCCGTC3') and $\mathrm{CZ}_{1} \mathrm{r}$ (5' CCGGATATCTCCTCGTGGTCGGCGGT 3'), $\mathrm{CZ}_{2}$ f (5' CGCGGATCCCGGCGTGGTCAACGTC $\left.3^{\prime}\right)$ and $\mathrm{CZ}_{2} \mathrm{r}$ (5'TGCTCTAGACCCTGTCCGTTCATC NNN 3'), respectively. The kanamycin resistance cassette (Kanr) was amplified by PCR using the primer pairs kanf (5' CCGGATATCTACAAGGGGTGTTATGAGCC 3') and kanr (5' CGCGGATCCTTAGAAAAACTCATC GAGCAT 3'). The final PCR products $\left(C Z_{1}: 993 \mathrm{bp}\right.$, $C Z_{2}$ : 992 bp, Kanr: 832 bp) were cloned into the pMD19-T vector, and used for sequencing to confirm the correct amplification. Fragments CZ1 and CZ2 were used as the left bridge and the right bridge, respectively. Three resulting DNA fragments were digested by the restriction enzymes and inserted into the EcoRV and $X b a \mathrm{I}$ sites of the pKC1139 vector to generate pKC1139-CZ1Kanr-CZ2 (pKC $\Delta$ otrC). The recombinant plasmid was demethylated and introduced into either M4018 or SR16. The screening of the otrC disruption mutants M4018/pKC $\Delta$ otrC and SR16/pKC $\Delta$ otrC followed standard procedures [30]. Confirmation of the $\operatorname{otr} C$ disruption was performed by the PCR amplification of kanr using genomic DNA of the mutants as a template.

\section{Effect of OtrC expression on drug susceptibility}

E.coli/pETC02 was grown in LB liquid medium with $50 \mu \mathrm{g} / \mathrm{ml}$ kanamycin, IPTG $(1 \mathrm{mM})$ and different concentrations of drugs at $37^{\circ} \mathrm{C}, 170 \mathrm{rpm}$ for $12 \mathrm{~h}$, and then resuspended in 1 volume of fresh LB. Then, $50 \mu \mathrm{l}$ cell suspension was spread immediately on the LB plates with $50 \mu \mathrm{g} / \mathrm{ml}$ kanamycin and $1 \mathrm{mM}$ IPTG and different concentration of drugs, the plates were cultured at $37^{\circ} \mathrm{C}$ for $12 \mathrm{~h}$ to determine the minimal inhibitory concentrations (MICs). Experiments were performed in triplicate using E. coli/pET28a as the negative control.

$S$. rimosus mutants M4018/pSEC and M4018/ $\mathrm{pKC} \Delta$ otrC were grown in TSB adding different concentrations of tested drugs with M4018/pSET152 at $28^{\circ} \mathrm{C}$ and $220 \mathrm{rpm}$; after $30 \mathrm{~h}$ growth, cells were collected by centrifugation and resuspended in 1 volume of TSB. Then, $50 \mu \mathrm{l}$ of fresh mycelium suspension was spread immediately on the TSB plates with different concentration of tested drugs. The MICs were measured after incubation for $3 \mathrm{~d}$ at $28^{\circ} \mathrm{C}$, and experiments were performed in triplicate.

Effect of OtrC expression on OTC production in $S$.rimosus The mutants of M4018 and SR16 were cultured on the MS plates at $28^{\circ} \mathrm{C}$ for $3-5 \mathrm{~d}$ along with the parental strains; spores were collected and inoculated into GYCS medium to a final concentration of $1 \times 10^{6}$ spores per $\mathrm{ml}$, after they were cultured at $28^{\circ} \mathrm{C}$ on a rotary shaker $(260 \mathrm{rpm})$ for $72 \mathrm{~h}$ as the seed culture. For an assessment of OTC production, $1 \%$ seed culture was transferred into $\mathrm{SC}$ medium and cultured at $30^{\circ} \mathrm{C}$ on a rotary shaker $(260 \mathrm{rpm})$ for $7 \mathrm{~d}$. The OTC productivity of $S$. rimosus strains were measured by high performance liquid chromatography analysis (HPLC). Then, $1 \mathrm{ml}$ culture samples were centrifuged at $12,000 \mathrm{rpm}$ for $10 \mathrm{~min}$ after the $\mathrm{pH}$ was adjusted to $\mathrm{pH}$ 1.5-1.7 using $9 \mathrm{~mol} / \mathrm{L}$ $\mathrm{HCl}$. The supernatants were filtered through a $0.22-\mu \mathrm{m}$ filter (Millipore, Bedford, MA) and $10 \mu \mathrm{l}$ samples were injected for analysis. Agilent 1100 HPLC system equipped with a 5- $\mu \mathrm{m}$ C18 (Kromasil, Sweden) column (4.6 by $200 \mathrm{~nm}$ ) was employed for the HPLC analysis. The mixture of $60 \% \mathrm{H}_{2} \mathrm{O}, 10 \%$ methanol, $20 \%$ acetonitrile and $10 \%$ phosphoric acid $(2 \mathrm{mM})$ was used for the mobile phase and applied with a constant flow rate of $0.8 \mathrm{ml} \mathrm{min}{ }^{-1}$ over $10 \mathrm{~min}$. The OTC detection wavelength was $350 \mathrm{~nm}$ [27].

\section{qRT-PCR analysis of transcription levels}

The transcription level of the otrC gene was analyzed by qRT-PCR as described previously [31]. S. rimosus cells were collected at different developmental stages during fermentation. Fresh tissues were used for total RNA extraction immediately using the AxyPrepTM multisource total RNA miniprep kit (Axygen, USA). The genomic DNA was removed by DNase I digestion, and the purity of the RNA samples was measured as the ratio of RNA concentration $(\mathrm{ng} / \mu \mathrm{l})$ to protein concentration $(\mathrm{ng} / \mu \mathrm{l})$ by Qubit ${ }^{\mathrm{TM}}$ RNA Assay Kits and Qubit ${ }^{\mathrm{TM}}$ Protein Assay Kits (Invitrogen, CA, USA), using the Qubit $^{\circledR} 2.0$ fluorometer (Invitrogen), according to the instructions provided by the manufacturer. RNA samples (RNA:protein ratio, 1.8-2.0) were selected and examined by $3 \%$ agarose gel electrophoresis to check their integrity prior to qRT-PCR analysis $[32,33]$. First strand cDNA synthesis was performed with a reverse transcription kit (TaKaRa, Japan) according to the manufacturer's instructions. Standard curve was consisting of a 10 -fold serial dilution series of five points which was prepared from cDNA samples $(35 \mathrm{ng} / \mu \mathrm{l})$ and each dilution was tested under a range of temperatures around the calculated Tm of the primers used in the experiments; untranscribed RNA samples were used as negative controls. 
The Cq values were determined for the optimization of qRT-PCR conditions.

qRT-PCR was assessed using SYBR ${ }^{\circledR}$ GC Premix Ex $\mathrm{Taq}^{\mathrm{TM}}$ kits (TaKaRa, Japan) and a CFX96TM 168 realtime PCR detection system (Bio-Rad, USA). The total $25 \mu \mathrm{l}$ reaction volume contained $1 \mu \mathrm{l}$ DNA, $0.2 \mu \mathrm{M}$ forward primer, $0.2 \mu \mathrm{M}$ reverse primer, and $1 \times \mathrm{SYBR}^{\circledR}$ Premix Ex $\mathrm{Taq}^{\mathrm{TM}}$, and the reaction conditions were as follows: $95^{\circ} \mathrm{C}$ for $30 \mathrm{~s}$, and 40 cycles of $95^{\circ} \mathrm{C}$ for $5 \mathrm{~s}, 55$ $61^{\circ} \mathrm{C}$ for $30 \mathrm{~s}$ and $72^{\circ} \mathrm{C}$ for $30 \mathrm{~s}$. Analysis of the melting curve was performed over a range of $55^{\circ} \mathrm{C}$ to $95^{\circ} \mathrm{C}$ for $5 \mathrm{~s}$ at the end of the PCR cycles. Three housekeeping genes, 16S rRNA, $h r d B$ and G6PDH ( $z w f 1)$ were used as reference genes to normalize the data $[32,34]$. The optimized Tm and cDNA concentration of each gene were used for qRT-PCR analysis. The primers for qRT-PCR were as follows: QotrCf (GTCACACGAGCGCCCTG GT) and QotrCr (CGCCGCCGAAGACGTACAC) were used for otrC transcriptional level analysis; QhrdBf (CTCTGTCATGGCGCTCA) and QhrdBr (ACGTTC TTCCACTGAGTGG) for the reference gene $h r d B$; Q16Sf (AGACACGGCCCAGACTC) and Q16Sr (CTG CTGAAAGAGGTTTACAAC) for 16S rRNA; Qzwff (ACTGGGCCAGAACGCCCT) and Qzwfr (AGTCCAT CGAGACGTCCCGTA) for $z w f 1$.

\section{Additional file}

Additional file 1: Figure $\mathbf{S 1}$. Construction of the recombinant plasmid pET28a-otrC (pETC02) for heterologous expression of OtrC in E. coli.

Figure S2. ATPase assay of OtrC-overexpressing and OtrC-nonexpressing cells with different reaction time. Figure $\mathbf{S 3}$. Construction of the recombinant plasmid pSET152-Erme ${ }^{*}$-otrC (pSEC) and identification of its integration in S. rimosus. Figure S4. Construction and identification of the recombinant plasmid pKC1139- $C Z_{1}-K a n r-C Z_{2}$ (pKC $\Delta$ otr C) for otrC disruption in S. rimosus.

\section{Competing interests}

The authors declare that they have no competing interests.

\section{Authors' contributions}

LY designed the approach, constructed the recombinant plasmids and mutants, and performed the ATPase activity and EB efflux assay, carried out bioinformatics research for conserved motifs analysis, prepared the draft the manuscript. XYY provided technical assistance with PCR amplification, plasmid identification and determine the minimal inhibitory concentrations of drugs. LW assisted with fermentation and OTC production measurement. MJG supervised LY, and participated in approach design, manuscript preparation. JC provided assistance on background studies, participated in manuscript preparation and editing. YPZ helped MIC determination and gave many useful suggestions. SLZ supervised LY for manuscript preparing and submitted it. All authors read and approved the final manuscript.

\section{Acknowledgements}

This work was supported by the National Basic Research Program of China (973 Project) (No. 2011CB200904, 2012CB721006), and a grant from the National High Technology Research and Development Program of China (863 Program) (No. 2012AA021201), and the Fundamental Research Funds for the Central Universities (ECUST).

\section{Author details}

'State Key Laboratory of Bioreactor Engineering, East China University of Science and Technology, 130 Meilong Road, Shanghai 200237, P.R. China. ${ }^{2}$ School of Life \& Science, Huzhou Teachers College, Zhejiang, Huzhou 313000, P.R. China.

Received: 31 March 2012 Accepted: 11 August 2012 Published: 20 August 2012

\section{References}

1. Gustot A, Smriti, Ruysschaert JM, MCHaourab H, Govaerts C: Lipid composition regulates the orientation of transmembrane helices in HorA, an ABC multidrug transporter. J Biol Chem 2010, 285(19):14144-14151.

2. Rodriguez-Garcia A, Santamarta I, Perez-Redondo R, Martin JF, Liras P: Characterization of a two-gene operon epeRA involved in multidrug resistance in Streptomyces clavuligerus. Res Microbiol 2006, 157(6):559-568.

3. Oliveira AS, Baptista AM, Soares CM: Conformational changes induced by ATP hydrolysis in an $A B C$ transporter: a molecular dynamics study of the Sav 1866 exporter. Proteins 2011, 79(6):1977-1990.

4. Choudhuri BS, Bhakta S, Barik R, Basu J, Kundu M, Chakrabarti P: Overexpression and functional characterization of an ABC (ATP-binding cassette) transporter encoded by the genes $d r r A$ and $d r r B$ of Mycobacterium tuberculosis. Biochem J 2002, 367:279-285.

5. Ward $A$, Reyes $C L$, $Y u$ J, Roth $C B$, Chang G: Flexibility in the $A B C$ transporter MsbA: alternating access with a twist. Proc Natl Acad of SCi USA 2007, 104(48):19005-19010.

6. Zou P, McHaourab HS: Alternating access of the putative substratebinding chamber in the ABC transporter MsbA. J Mol Biol 2009, 393(3):574-585.

7. Chang G, Roth CB: Structure of MsbA from E. coli: a homolog of the multidrug resistance ATP-binding cassette $(A B C)$ transporters. Science 2001, 293(5536):1793-1800.

8. Linton KJ: Structure and function of ABC transporters. Physiology (Bethesda) 2007, 22:122-130.

9. Linton KJ, Higgins CF: Structure and function of $A B C$ transporters: the ATP switch provides flexible control. PflügersArchiv European Journal of Physiology 2007, 453(5):555-567.

10. Grote M, Polyhach Y, Jeschke G, Steinhoff HJ, Schneider E, Bordignon E: Transmembrane signaling in the maltose $A B C$ transporter MalFGK2-E: periplasmic MalF-P2 loop communicates substrate availability to the ATP-bound MalK dimmer. J Biol Chem 2009, 284(26):17521-17526.

11. Loo TW, Bartlett MC, Clarke DM: The "LSGGQ" motif in each nucleotidebinding domain of human P-glycoprotein is adjacent to the opposing Walker A sequence. J Biol Chem 2002, 277:41303-41306.

12. Qiu J, Zhuo Y, Zhu D, Zhou X, Zhang L, Bai L, Deng Z: Overexpression of the $A B C$ transporter $A v t A B$ increases avermectin production in Streptomyces avermitilis. Appl Microbiol Biotechnol 2011, 92(2):337-345.

13. Malla S, Niraula NP, Liou KK, Sohng JK: Self-resistance mechanism in Streptomyces peucetius: Overexpression of $d r r A, d r r B$ and $\operatorname{drrC}$ for doxorubicin enhancement. Microbiol Res 2010, 165(4):259-267.

14. MCMurry LM, Levy SB: Revised sequence of OtrB (tet347) tetracycline efflux protein from Streptomyces rimosus. Antimicrob Agents Chemother 1998, 42:3050

15. Petkovic H, Cullum J, Hranueli D, Hunter IS, Perić CN, Pigac J, Thamchaipenet A, Vujaklija D, Long PF: Genetics of Streptomyces rimosus, the oxytetracycline producer. Microbiol Mol Biol Rev 2006, 70:704-728.

16. Guilfoile PG, Hutchinson R: A bacterial analog of the mdr gene of mammalian tumor cells is present in Streptomyces peucetius, the producer of doxorubicin and daunorubicin. Proceedings of the National Academy of Sciences USA 1991, 88:8553-8557.

17. Fernandez-Moreno MA, Carbo L, Cuesta T, Vallin C, Malpartida F: A silent ABC transporter isolated from Streptomyces rochei F20 induces multidrug resistance. J Bacteriol 1998, 180(16):4017-4023.

18. Zhang $\mathrm{H}$, Pradhan $\mathrm{P}$, Kaur $\mathrm{P}$ : The extreme $\mathrm{C}$ terminus of the $\mathrm{ABC}$ protein DrrA contains unique motifs involved in function and assembly of the DrrAB complex. J Biol Chem 2010, 285(49):38324-38336.

19. Kaur P, Rao DK, Gandlur SM: Biochemical characterization of domains in the membrane subunit DrrB that interact with the $A B C$ subunit DrrA: identification of a conserved motif. Biochemistry 2005, 44:2661-2670. 
20. Malla S, Niraula NP, Liou K, Sohng JK: Improvement in doxorubicin productivity by overexpression of regulatory genes in Streptomyces peucetius. Res Microbiol 2010, 162:109-117.

21. Smanski MJ, Peterson RM, Rajski SR, Shen B: Engineered Streptomyces platensis Strains that overproduce antibiotics platensimycin and platencin. Antimicrob Agents Chemother 2009, 53(4):1299-1304.

22. Xu D, Kim TJ, Park ZY, Lee SK, Yang SH, Kwon HJ, Suh JW: A DNA-binding factor, ArfA, interacts with the bldH promoter and affects undecylprodigiosin production in Streptomyces lividans. Biochem Biophys Res Commun 2009, 379(2):319-323.

23. Yuan LZ, Rouviere PE, Larossa RA, Suh W: Chromosomal promoter replacement of the isoprenoid pathway for enhancing carotenoid production in E. coli. Metab Eng 2006, 8(1):79-90.

24. Steigedal M, Valla S: The Acinetobacter sp. chnB promoter together with its cognate positive regulator $\mathrm{ChnR}$ is an attractive new candidate for metabolic engineering applications in bacteria. Metab Eng 2008, 10(12):121-129.

25. MacNeil DJ, Gewain KM, Ruby CL, Dezeny G, Gibbons PH, MacNeil T: Analysis of Streptomyces avermitilis genes required for avermectin biosynthesis utilizing a novel integration vector. Gene 1992, 111:61-68.

26. Kieser T, Bibb MJ, Buttner MJ, Chater KF, Hopwood DA: Practical Streptomyces genetics. Norwich, United Kingdom: John Innes Foundation; 2000.

27. Wang JY, Yang SS: Morphogenesis, biomass and oxytetracycline production of Streptomyces rimosus in submerged cultivation. annual scientific report of national laboratories of foods and drugs. Depart of Health, Executive Yuan, Taiwan R.O.C 1996, 14:68-78.

28. Baykov AA, Evtushenko OA, Avaeva SM: A malachite green procedure for orthophosphate determination and its use in alkaline phosphatase-based enzyme immunoassay. Anal Biochem 1988, 171(2):266-270.

29. Sakamoto K, Margolles A, van Veen HW, Konings WN: Hop resistance in the beer spoilage bacterium Lactobacillus brevis is mediated by the ATP-binding cassette multidrug transporter HorA. J Bacteriol 2001, 183(18):5371-5375.

30. Bierman M, Logan R, O'Brien K, Seno ET, Rao RN, Schoner BE: Plasmid cloning vectors for the conjugal transfer of DNA from Escherichia coli to Streptomyces spp. Gene 1992, 116(1):43-49.

31. Yu L, Cao N, Wang L, Xiao C, Guo M, Chu J, Zhuang Y, Zhang S: Oxytetracycline biosynthesis improvement in Streptomyces rimosus following duplication of minimal PKS genes. Enzyme Microb Technol 2012, 50(6-7):318-324

32. Taylor S, Wakem M, Dijkman G, Alsarraj M, Nguyen M: A practical approach to RT-qPCR-publishing data that conform to the MIQE guidelines. Methods 2010, 50:S1-S5.

33. Bustin SA, Benes V, Garson JA, Hellemans J, Huggett J, Kubista M, Mueller R, Nolan T, Pfaffl MW, Shipley GL, Vandesompele J, Wittwer CT: The MIQE guidelines: minimum information for publication of quantitative real-time PCR experiments. Clin Chem 2009, 55(4):611-622.

34. Li R, Liu G, Xie ZJ, He XH, Chen WQ, Deng ZX, Tan HR: PolY, a transcriptional regulator with ATPase activity, directly activates transcription of polR in polyoxin biosynthesis in Streptomyces cacaoi. Mol Microbiol 2010, 75(2):349-364

\section{Submit your next manuscript to BioMed Central and take full advantage of:}

- Convenient online submission

- Thorough peer review

- No space constraints or color figure charges

- Immediate publication on acceptance

- Inclusion in PubMed, CAS, Scopus and Google Scholar

- Research which is freely available for redistribution

Submit your manuscript at www.biomedcentral.com/submit 